Opinion

\title{
Outside the Site Boundary
}

\author{
Chan Kwan Fai Timothy* \\ Faculty of Science and Technology, Technological and Higher Education Institute of Hong Kong, Hong Kong
}

*Corresponding author: Chan Kwan Fai Timothy, Faculty of Science and Technology,

Technological and Higher Education Institute of Hong Kong, Hong Kong.

\author{
Received Date: July 15, 2019 \\ Published Date: July 17, 2019
}

\section{Opinion}

Site boundary is an important concern in the civil engineering field. Site boundary represents the extent of liability a person, group of people or even the whole society owed. Two issues may be resulted if our works have been implemented outside the site boundary. First, it may trespass to others and may damages their properties. Second, it may increase the cost of construction due to money spent on dispensable works. Owing to the extra cost and liability resulted, civil engineer used to consider the issue of site boundary.

The concept of site boundary pushes civil engineer to create a special practice in planning works. They may consider the liability and, thus, the extent of their works before the concern of social value and the product function in the society. A lot of effort will be paid on clarification of responsibility of a particular works. The engineers are tended to stand on a side after they have clarified that the liability is not belong to them. This custom makes engineers concerned only on their own job rather than the community where they live.

There are so many problems in the society of Hong Kong required improvement contributed by an energetic and responsible person. Engineers are the huge human resource in the society. However, this concept of site boundary makes them standstill. The action to serve the community by their professional knowledge may put them into a trap with liability that originally not belong to them. Moreover, their kindly action may initiate extra construction works that the public may query the responsibility of the cost and the intention of the kindly engineer. It will be an unnecessary trouble of the engineer.
However, the society is the place where we live. We can't treat it as a hotel. How can we live in the society comfortably if it gets worse and worse? Engineers construct the infrastructure for the future of society. How come an engineer cannot concern the problem within the society? It may a calling of engineers to get themselves outside the site boundary of their mind.

But, how can we serve the community effectively without engaged in activities with liability that originally not owed by us? It is the role of us with the matter concerned. If we are practicing as engineers, we are engineers. If we are concerning some social issues, we are common people. While we try to help the society with our engineering knowledge and experience, we serve the society without engage into dispensable liability under the role of common person. The technical way may ensure the causation of the consequence not be created by the interference of the engineer. The engineer can be a source of knowledge and innovation.

The problem of engineer does not involve in service of the society is not the way of their interaction, but their worry of the involvement of liability. It might need the change of the mind of engineers in their role in the society. The site boundary bound not only engineers' sites, but also their minds.

\section{Acknowledgement}

None.

\section{Conflict of Interest}

No conflict of interest. 